\title{
The size of occlusal rest seats prepared for removable partial dentures
}

\author{
P. F. Culwick, ' P. G. T. Howell , ${ }^{2}$ and M. J. Faigenblum , 3
}

\begin{abstract}
Objective The aim of this study was to test whether rest seats cut by a group of general dental practitioners for a removable partial denture differed in size and shape from those prepared by either a group of postgraduate students or their academic teachers.

Method The occlusal surfaces of a number of plastic teeth were scanned by a laser profilometer. Each tooth was then placed in a set of articulated phantom head dental arches. 30 dental practitioners, 16 postgraduates and 11 dental academics were asked to cut a rest seat preparation in the mesial marginal ridge suitable for the construction of a removable chromium cobalt partial denture. The tooth was removed from the models, rescanned, and this data converted to grey level images for measurement of the width, length and area of each rest seat. Depth was calculated as the difference between the pre and post preparation scanned profiles.

Results There was a wide variation in the size of the individual rest seat preparations. There was no significant difference between the measured parameters from the images of the preparations made by academic staff and postgraduate students. The two sets of data were therefore combined. The length, width and area of the rest seats prepared by the staff and postgraduate group were significantly greater than those cut by the dental practitioner group. However, there was no significant difference in the depths measured. The outline form of the rests prepared by the dental practitioners was often round with sharply defined margins contrasting with the smooth triangular preparation the staff and postgraduates prepared.

Conclusion A 'refresher' in tooth modification for GDPs designing partial dentures would improve the long term success of the prosthesis.
\end{abstract}

\footnotetext{
The changing pattern of dental disease in the UK has led to the 1 retention of teeth for far longer than has previously been the case. ${ }^{1-3}$ Because of this there are currently more partial dentures made than complete ones. Dental Practice Board data show that there has been a steady decline in the provision of dentures under the NHS during the past decade, with a reduction of $47 \%$ for complete dentures and $25 \%$ for partial dentures. ${ }^{4,5}$ A patient's reasons for wearing a partial denture are ascribed to improved appearance
}

\footnotetext{
${ }^{1}$ Surgeon Commander(D) Royal Navy, Northwood Headquarters, Middlesex HA6 3HP, ${ }^{2}$ Senior Lecturer, ${ }^{3}$ Honorary Clinical Senior Lecturer, Department of Prosthetic Dentistry, The Eastman Dental Institute, University of London, 256 Grays Inn Road, London WC1X 8LD.

Correspondence to: P. G. T. Howell, Department of Prosthetic Dentistry, The Eastman Dental Institute, University of London, 256 Grays Inn Road, London WC1X 8LD

email:p.howell@eastman.ucl.ac.uk

REFEREED PAPER

Received 05.08.99; accepted 27.04.00

(c) British Dental Journal 2000; 189: 318-322
}

and chewing ability; ${ }^{6}$ a dentist intends, in addition to restore the occlusion, prevent tooth movement, and to distribute the masticatory forces equitably over the remaining teeth and soft tissues. ${ }^{7}$

Partial dentures, when made of acrylic resin, are rarely designed to use occlusal rests and are therefore prevented from apical movement mainly by the resistance of the underlying mucosa to the denture base. Those using a cast metal denture framework will readily allow the inclusion of addition features such as occlusal rests during their construction. The remaining teeth then assist in distributing the masticatory loads over the whole dental arch with only a proportion passing through to the mucosa beneath the edentulous saddle areas. Modification of the supporting teeth ensures that the rest can be of adequate thickness to prevent its distortion under load; that the rest does not interfere with the occlusion, and that the tooth is axially loaded. ${ }^{8-14}$ The rest seat also gives a positive position for its location and prevents the whole prosthesis from moving during functional loading. ${ }^{15}$ The design and placement of rest seats in enamel, light cured resins, silver amalgam alloy or cast restorations is part of the undergraduate curricula in the UK and USA. ${ }^{16,17}$ In the 1970s it was uncommon for the practitioner in a British general dental practice to design his own partial dentures or to make any tooth modification prior to recording his working impression. ${ }^{18,19}$ More recently Basker et al. showed an improvement in this direction. ${ }^{20}$

In general, the design of rest seat preparations are based upon personal opinion and experience, however typically the outline form follows that described by Henderson and Steffel by: ${ }^{21}$

- Having a triangular or spoon shape, with no sharp edges or 'line angles'

- Being as long as it is wide

- Having its width half that of the adjacent buccal and lingual cusps

- Being thick enough for strength and rigidity

- Having a floor inclined down toward the centre of the tooth.

Kratochvil described a similarly shaped rest seat and suggested that the width should be the size of a No. 6 or 8 round bur (ie $1.9-2.3 \mathrm{~mm}) .{ }^{15}$ Where there is inadequate inter-occlusal space or the enamel thickness is insufficient for a rest seat minor adjustment of the opposing tooth may be needed. ${ }^{8}$ In summary an occlusal rest seat preparation should be smooth and saucer-shaped; about $1 \mathrm{~mm}$ thick; and around $1 / 3$ width and $1 / 3$ the length of the tooth. Much longer rests, extending for more than half the mesio-distal width of a tooth, have been occasionally advocated and particularly where a rotational path of insertion is selected for the denture. ${ }^{14,15,22,23}$

When assessing the outcome of a rest seat preparation of the tooth surface the linear measurements of the length and width of a rest seat preparation are relatively straightforward to obtain and only require a 'ruler' of the appropriate precision. But the assessment of depth is more complex and cannot be determined from a single measurement procedure. The shape of the tooth before any tissue removal must be known first. For simple, regular or geometric shapes, this reconstruction is relatively straightforward. However where the 
surface has a complex three-dimensional shape, for example that of the occlusal surface of a molar tooth, this reconstruction is difficult if not possible. ${ }^{25}$ Many instruments and techniques have been used in the metrology of surfaces including contact profilometry, close range photogrammetry using a photographic camera, a reflex microscope or a scanning electron microscope. These methods all have advantages and disadvantages related to their ease of use, accuracy and range of measurement. This work used a laser profilometer capable of non-contact measurement of small height differences over a large vertical and horizontal range.

With the changed pattern of treatment it is appropriate to test the ability of the present graduated dentist to adequately provide this form of treatment. The preparation of a suitable denture support impinges greatly on the long-term success of the prosthesis and the health of the remaining dentition. The aim of this paper is to compare the size and shape of a rest seat prepared for a cast chromium cobalt removable partial denture by three groups of dentists with differing levels of professed expertise in the discipline.

\section{Method and materials}

Fifty-seven qualified dentists took part in this study. Thirty were general dental practitioners (GDPs) attending an extended, part time, course in restorative dentistry where the module on removable partial dentures had not yet started. A second group comprised sixteen postgraduates (PG) who were currently undertaking a Masters programme of which a major component was removable prosthodontics. Eleven members of the academic teaching staff (Staff) formed the final group in the study.

The right maxillary second premolars and first molars were removed from a set of phantom head models (Columbia Dentoform Corporation, Long Island City, NY, USA) and the sockets filled with wax before the models were duplicated in silicone elastomer (Deguform ${ }^{\circledR}$, Degussa AG, Postfach, Germany). A Dentoform
Ivorine second molar was carefully seated in the maxillary mould on the right-hand side. Both moulds were poured in dental stone. The base of the maxillary cast was adjusted to give access to the Ivorine tooth so that it, and the others used in the study, could be placed and removed to measure its occlusal form. The upper cast was then mounted on a Dentatus ARL articulator (AB Dentatus, S12653 Hägersten, Sweden) with its occlusal plane lying horizontal, and the tip of the incisors level with the horizontal mark on the pin. The lower cast of the intact arch was mounted to the upper cast to give a maximal intercuspal contact, with the mesio-buccal cusp of the lower second molar occluding with the mesial marginal ridge of the opposing second molar tooth.

Each Ivorine tooth used in this study had its occlusal surface mapped (Fig. 1a) by the Proscan 1000 laser scanning profilometer (Scantron Industrial Products Ltd, Taunton, UK). The tooth was placed in a specially constructed jig made from acrylic tray resin and machined plexiglas (Perspex ${ }^{\circledR}$, ICI Ltd, UK). The jig ensured that each tooth was held accurately and reproducibly orientated under the Proscan laser. During initial tests it was found that the laser was unable to measure the steep proximal contour of the tooth, so the jig was adjusted by $15^{\circ}$ to the distal to ensure this part of the tooth was in the laser's line of sight. The measured ' $Z$ ' axis was at $15^{\circ}$ to the true vertical and required a correction factor of Cosine $15^{\circ}(=0.9659)$. This was considered to give a negligible effect and was omitted. The jig was screwed to the profilometer's computer controlled, stepper motor, stage with the mesio-distal and buccopalatal directions lying parallel to the $\mathrm{x}$ and $\mathrm{y}$ stage movements. Mapping consisted of scanning an area up to $6.40 \mathrm{~mm}$ square with a step size of $0.010 \mathrm{~mm}$ between measured points with a vertical resolution of $0.001 \mathrm{~mm}$ provided by the KL135A laser. The measurements of the height at each point were stored as ASCII data filed on disc for later analysis. Each tooth was then uniquely identified and placed in the maxillary cast on the Dentatus articulator for the
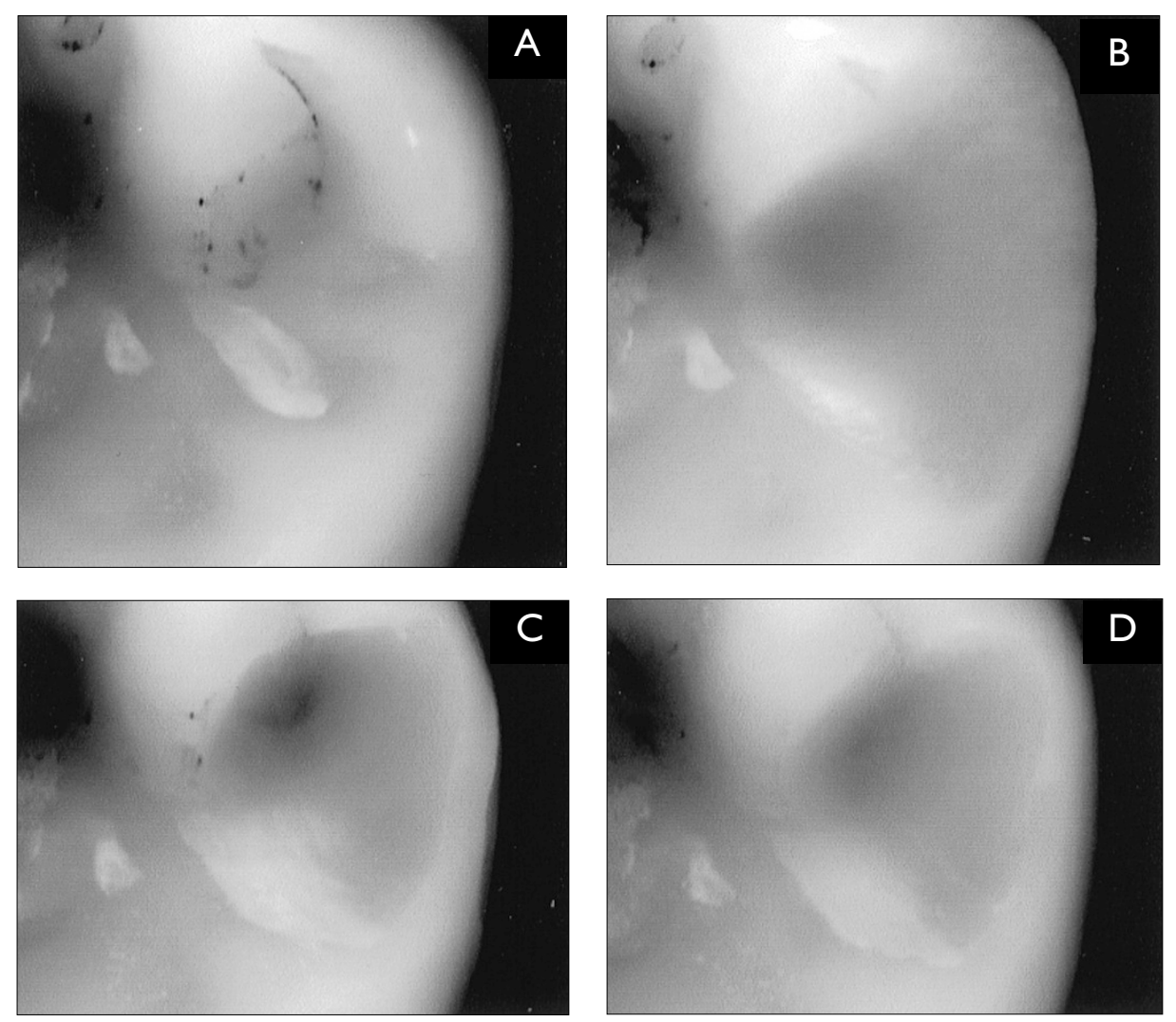

Fig. Ia) An image derived from Proscan 1000 data of an upper right Dentoform second molar phantom head tooth. Ib-d) images of rest seat preparations cut by members of the Staff + PG group 


\section{RESEARCH prosthetics}
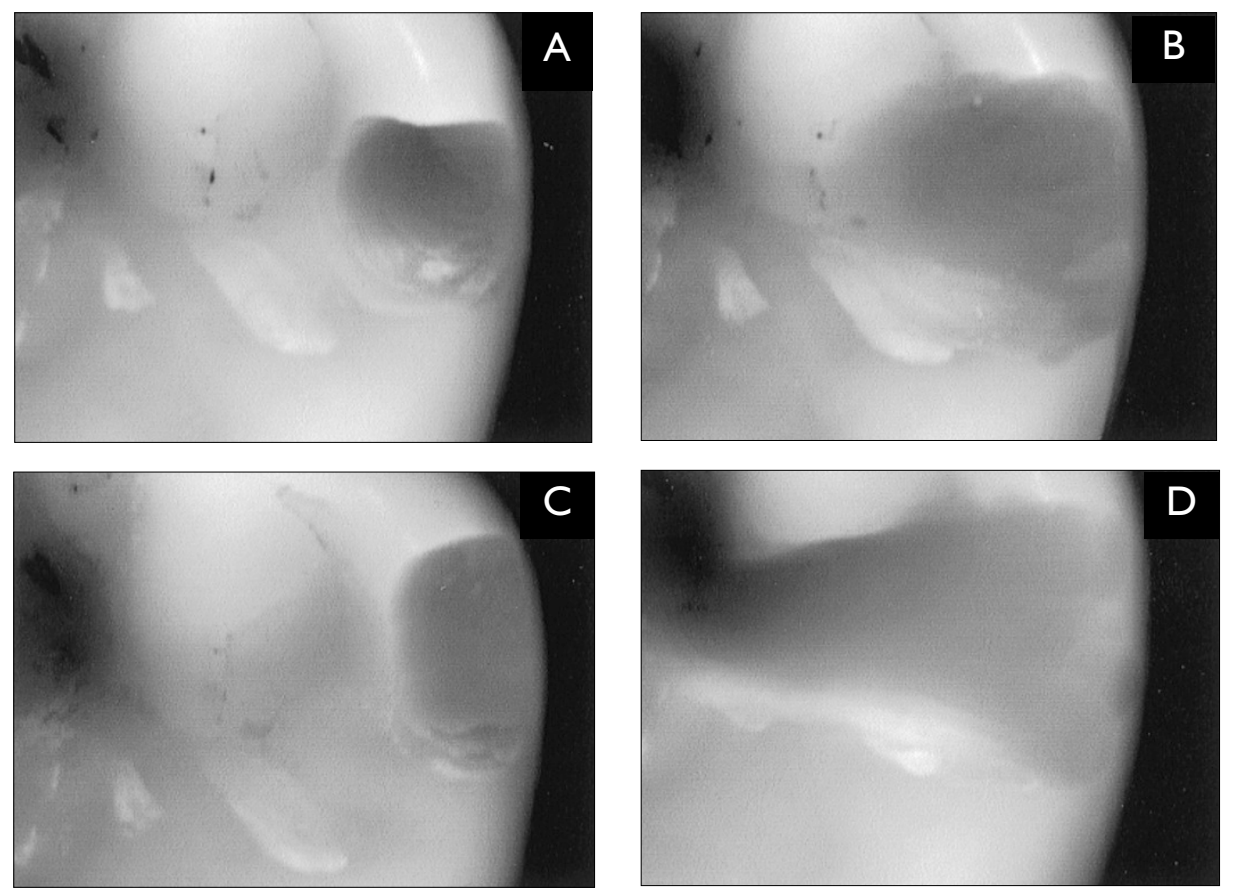

Fig. 2a-d Rest seat preparations cut by members of the GDP group

preparation of the rest seat. The articulated models were handed to each dentist who was then asked to cut a mesial rest seat in the plastic molar tooth using the methods that they would normally employ in their routine clinical environment. Each dentist was provided with a high and a slow speed handpiece; a wide selection of diamond, steel and tungsten carbide burs; and articulating paper. After preparation each tooth was removed from the articulator, and returned to the orientation jig, where its occlusal surface was rescanned with the laser profilometer and the new height coordinate data was stored.

Each raw data file of height values was converted, by specially written software, into a 256-grey level image with a standard TIFF image format. These images were then studied and the dimensions, length and width, and area of the rest seat made with analySIS image analysis software (Soft-Imaging Software GmbH, D-48153 Münster, Germany) by a single operator. Additionally, the pre- and post-preparation ASCII data files were imported into a spreadsheet where corresponding profiles were made through the centre of each tooth including the site of the rest seat. The depth of the rest seat preparation at the marginal ridge was then measured as the difference in vertical distance between the two lines. Data were entered into Minitab (Minitab Inc, 3081 Enterprise Drive, State College, PA, USA) to provide descriptive statistics; correlate values according to the operator; and to carry out the Student ' $\mathrm{t}$ ' tests to compare the differences between the means of the various dimension of the rest seat.

\section{Results}

While scanning a test object of known dimensions routinely checks the accuracy of the measurements made by the Proscan, this study did not use its full capabilities as measurements were made only to the nearest $0.01 \mathrm{~mm}$. The ability of one operator to measure distances in the images of the rest seat preparation was assessed by repeating these measurements on ten separate occasions from one sample. A $95 \%$ confidence limit of $\pm 0.012 \mathrm{~mm}$ on distances of $2.91 \mathrm{~mm}$ was obtained.

There was a wide variety of shapes and sizes to the prepared rest seats (Figs 1 and 2). The mean and 95\% confidence interval for the width, length, depth and area of the rest seats for each group in the study are shown in Tables 1 and 2. No significant difference, at $P<0.05$, was found between the postgraduates and their
Table I Measurements of the length and width of the rest seats prepared by the general dentists (GDP), the postgraduates (PG) and their academic tutors (Staff), and the combined data for postgraduates and academics (Staff + PG). The data shown are the mean values and the $95 \%$ confidence interval

\begin{tabular}{lccccc}
\hline Group & $\mathrm{N}$ & \multicolumn{2}{c}{$\begin{array}{c}\text { Length } \\
\mathrm{mm}\end{array}$} & \multicolumn{2}{c}{$\begin{array}{c}\text { Width } \\
\mathrm{mm}\end{array}$} \\
& & Mean & $95 \% \mathrm{Cl}$ & Mean & $95 \% \mathrm{Cl}$ \\
\hline GDP & 30 & 2.94 & 0.35 & 3.36 & 0.38 \\
PG & 16 & 3.38 & 0.22 & 3.70 & 0.41 \\
Staff & $\mathrm{II}$ & 3.52 & 0.65 & 4.30 & 0.67 \\
& & & & & \\
Staff + PG & 27 & 3.44 & 0.29 & 3.94 & 0.37 \\
\hline
\end{tabular}

Table 2 Measurements of the depth and projected area of the rest seats prepared by the general dentists (GDP), the postgraduates (PG) and their academic tutors (Staff), and the combined data for postgraduates and academics (Staff + PG). The data shown are the mean values and the $95 \%$ confidence interval

\begin{tabular}{lccccc}
\hline Group & $\mathrm{N}$ & \multicolumn{2}{c}{$\begin{array}{c}\text { Depth } \\
\mathrm{mm}\end{array}$} & \multicolumn{2}{c}{$\begin{array}{c}\text { Area } \\
\mathrm{mm}^{2}\end{array}$} \\
& & Mean & $95 \% \mathrm{Cl}$ & Mean & $95 \% \mathrm{Cl}$ \\
GDP & 30 & 0.78 & 0.13 & 7.00 & 1.32 \\
PG & 16 & 0.68 & 0.12 & 9.23 & 1.27 \\
Staff & 11 & 0.65 & 0.16 & 10.44 & 3.30 \\
Staff + PG & 27 & 0.67 & 0.09 & 9.72 & 1.52 \\
\hline
\end{tabular}

academic staff for any dimensions or area measurement of the rest seats. The data from these two groups was therefore pooled to form an aggregated Staff + PG group (Table 1,2), and this was used for all further statistical comparisons with the GDP group. The bucco-palatal width of the rest seats ranged between 2.04-6.80 $\mathrm{mm}$. Both these extreme values were found in the GDP group. Overall the rest seats prepared by the GDPs were narrower 


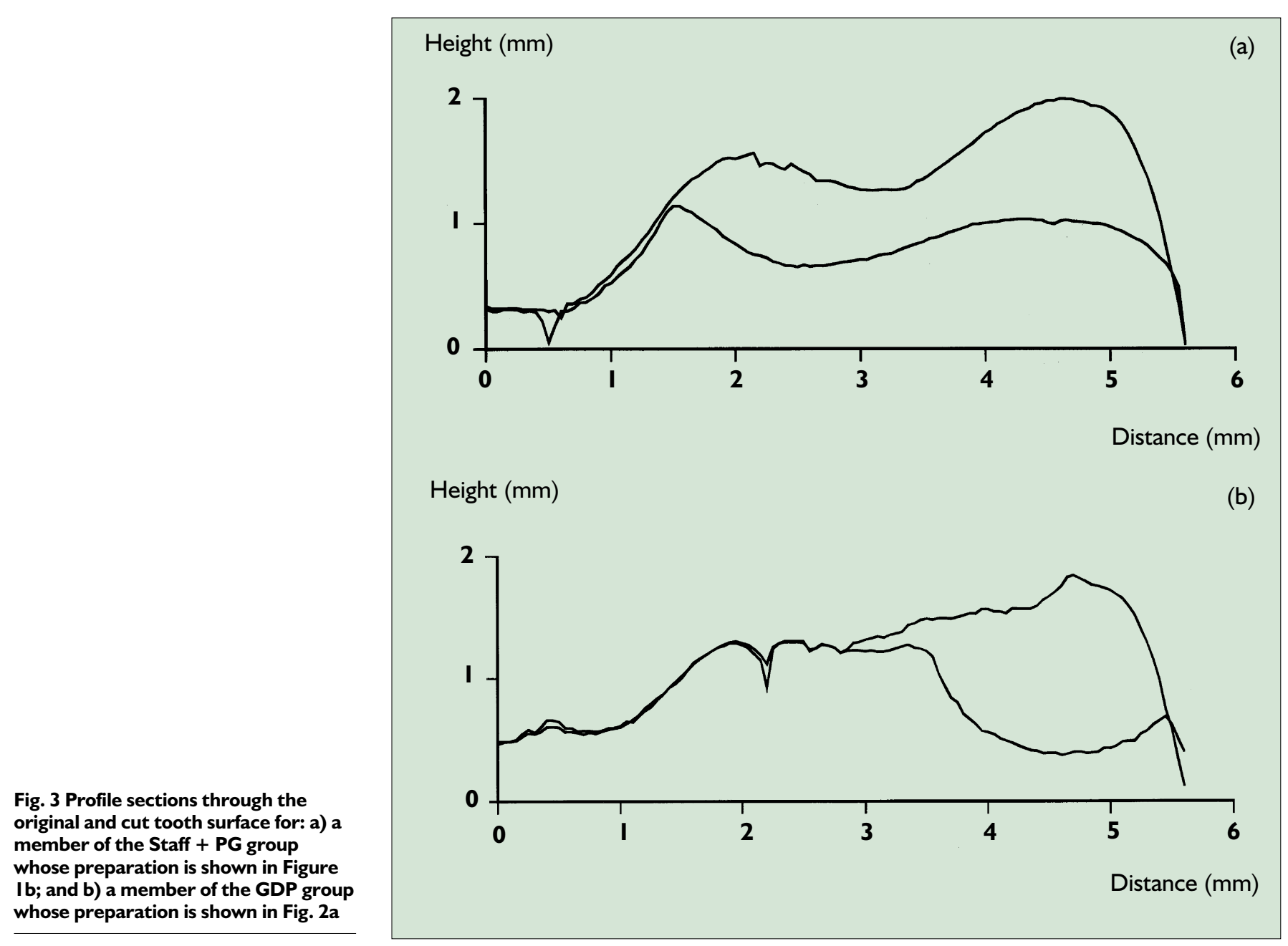

than those prepared by Staff + PG and this difference was statistically significant $(0.05<P<0.01)$. There was a large spread in the mesio-distal length measurements for the prepared rest seats $(1.49-6.10 \mathrm{~mm})$. Those cut by the Staff + PG group were much longer than those of the GDPs, and this difference was significant $(0.05<P<0.01)$.

The support potential of the prepared rest can be assessed by measuring its projected area on the tooth surface. As before there was a marked range of sizes with an almost tenfold difference between the smallest and the largest $(2.63-24.34 \mathrm{~mm} \approx)$. The smallest was cut by a member of the GDP group and the largest by one of the Staff +PGs. Overall, those rests prepared by the Staff + PGs was considerably larger than those of GDP group, and this difference was very significant $(0.01<P<0.001)$.

The depth of the rest seat preparation was measured at the crest of the marginal ridge, as the difference between the midline mesiodistal profiles of the prepared and unprepared teeth (Fig. 3). The depth measurements ranged between $0.03-1.4 \mathrm{~mm}$, with both these extreme values being found within the GDP group. However, the difference between the GDPs and the Staff + PG group was not significant $(P>0.05)$.

The Staff + PG group generally prepared rests seats with a smooth contour blending into the surrounding tooth surface (Fig. 1b, 1c and 1d). In contrast, the rest seats prepared by the GDP group often appeared as a round depression indicative of being cut by the single application of a round bur placed on the marginal ridge (Fig. 2). On occasion a deep trench across the occlusal surface was found (Fig. 2d). These differences were confirmed by the smoother outlines to the cross-sectional, and mesio-distal profiles through the rest seat preparations by the Staff + PG compared with the GDPs (Fig. 3a and $3 \mathrm{~b}$ respectively).

\section{Discussion}

This study used plastic phantom head teeth, rather than natural teeth, as they represent a model tooth with identical size, occlusal form and standardised occlusion. It was felt that the uniformity of shape and texture outweighed any differences caused by cutting characteristics. However, it is possible that cutting the softer plastic tooth would have been noticeable to the GDPs and could explain some of the differences in rest seat preparation size.

The rest seats prepared by the operators showed a wide variation both within and between the groups taking part in this study. A fairly common feature among the rest seat preparations of the GDPs was that they had sharply delineated margins, that appeared to have been produced by a round bur punching into the tooth surface (Fig. 2). There was little evidence of smoothing of the rest seat after the initial preparation to make the margins blend in with the surrounding tooth surface. By comparison, those prepared by the Staff + PG tended to have a smoother contour blending into that of the surrounding tooth surface and extending to create a wider and longer rest. These differences may well be explained by the almost universal use of high speed burs by the GDPs as opposed to the slow speed stones and finishing burs preferred by the academic staff and postgraduates.

The mesio-distal length and the bucco-lingual width of the Dentoform upper second molar tooth are $10.1 \mathrm{~mm}$ and $10.9 \mathrm{~mm}$ respectively. The mean length of the rest seat preparation cut by the Staff + PG group was very close to the 'ideal' length of $3.37 \mathrm{~mm}$ 


\section{RESEARCH prosthetics}

while those of the GDP group were markedly smaller. The width of the rest seats cut by Staff + PG and the GDPs closely bracketed that of the notional ideal width of $3.63 \mathrm{~mm}$. The depth of the rest seat preparation would represent the contact point of the mesio-buccal cusp of the lower second molar lower and necessitate the position where the greatest tooth reduction to provide adequate thickness of chrome-cobalt for strength and rigidity. Nearly all operators, Staff + PG and GDPs alike under-prepared the tooth in a position where the enamel is of the order of $2 \mathrm{~mm} .{ }^{32}$ The only option, if the thickness of the rest was not to be jeopardised, would be to reduce to the height of the opposing cusp which in the experimental setup had occluded firmly against the marginal ridge.

The area of the rest seats cut by the Staff + PG group was in general larger than those of the GDPs giving a substantial increase in the support potential for the denture.

\section{Conclusion}

The Proscan proved a useful tool with which to scan the 3-D topography of the occlusal surface of a tooth. The numerical data output enabled both profiles through the rests seat preparation to be plotted and, after conversion, a grey level image for analysis and display.

The size and shape of the rest seat preparations varied widely between the dentists taking part in this study, however no statistical difference was found between academic staff and postgraduate groups for any of the measured parameters. As a result their data was combined. The new Staff + PG group prepared larger rest seats than their general dental practitioner colleagues, being wider and longer and with a greater support area. These differences were significant. There was no statistical difference in the depth of the prepared rest seat between the two groups.

The Staff + PG group, in line with accepted practice, produced rest seats with an outline form which blended smoothly into the tooth surface. This was in marked distinction to the rest seat preparations of the GDP group which had a sharp definite outline form cut with the single application of a high speed bur.

With the increase in the number of dentists designing their own partial dentures, this study would indicate the need for 'a refresher' in tooth modification and rest seat preparation to ensure the long term successful outcome for their prostheses.

This paper was given as an oral presentation before the 46 th British Society for the Study of Prosthetic Dentistry Annual Conference in Liverpool in March 1999.

1 Downer M C. The improving dental health of United Kingdom adults and prospects for the future. Br Dent J 1991; 170: 154-158.

2 Downer M C. The changing pattern of dental disease over 50 years. Br Dent J 1998; 185: 36-41.

3 Todd J E, Lader D. Adult Dental Health 1988 United Kingdom. London:
HMSO, 1991.

4 Dental Practice Board - Digest of Statistics 1986-87. Eastbourne: Dental Practice Board, East Sussex, UK.

5 Dental Practice Board-Digest of Statistics 1997-98. Eastbourne: Dental Practice Board, East Sussex, UK.

6 Watt D M, MacGregor A R. Designing Partial Dentures. 2nd ed. Bristol: Wright, 1984.

7 Lechner S K, MacGregor A R. Removable Partial Prosthodontics. 1st ed. London: Wolfe, 1994.

8 Walter J D. Partial denture techniques. Br Dent J 1980; 148: 13-16.

9 MacGregor A R, Miller T P G, Farah J W. The support of bounded saddles. J Dent 1983; 11: 139-150.

10 Lammie G A, Laird W R E. Osborne and Lammie's Partial Dentures. 4th ed. London: Wolfe, 1986.

11 Likeman P R, Juszczyk A S. An examination of cingulum rest seats in incisor and canine teeth. Eur J Prosthodont Restor Dent 1993; 4: 165-171.

12 Kratchovil F K. Influence of occlusal rest position and clasp design on movement of abutment teeth. J Prosthetic Dent 1963; 13: 114-124.

13 Smith B J. Abutment preparation for removable partial dentures. In: Restoration of the partially dentate mouth. Bates J F, Neil D J, Preiskel H W (eds). Chicago: Quintessence Pub Co, 1984, Ch 17 pp259-271.

14 Rudd R W, Bange A A, Rudd K D, Montalvo R. Preparing teeth to receive a removable partial denture. J Prosthetic Dent 1999; 82: 536-549.

15 Kratochvil F J. Partial Removable Prosthodontics. 1st ed. Philadelphia: WB Saunders Co, 1988.

16 Schwarz W D, Barsby M J. Survey of the teaching of partial denture construction in dental schools in the United Kingdom. J Dent 1979; 7: 1-8.

17 Firtell D N, Kouyoumdjian J H, Holmes J B. Attitudes toward abutment preparation for RPD. J Prosthetic Dent 1986; 55: 131-133.

18 Schwarz W D, Barsby M J. Design of partial dentures in dental practice. J Dent 1978; 6:166-170.

19 Schwarz W D, Barsby M J. A survey of the practice of partial denture prosthetics in the United Kingdom. J Dent 1980; 8: 95-101.

20 Basker R M, Harrison A, Davenport J C, Marshall, J L. Partial denture design in general dental practice - 10 years on. Br Dent J 1988; 165 : 245-249.

21 Henderson D, Steffel V L. McCracken's Removable Partial Prosthodontics: 4th ed. St Louis: C V Mosby, 1973.

22 Stratton R J, Wiebelt F J. An Atlas of Removable Partial Denture Design. Chicago: Quintessence Publishing Co Inc, 1988.

23 Firtel D N, Jacobsen T E. Removable partial dentures with rotational paths of insertion: problem analysis. J Prosthetic Dent 1983; 50: 8-15.

24 Boyde A, Howell P G T, Franc F. Simple S E M stereophotogrammetric method for three-dimensional evaluation of features on flat substrates. J Microscopy 1986; 143: 257-264.

25 Ashmore H, Van Abbe N J, Wilson S J. The measurement in vitro of dentine abrasion by toothpaste. Br Dent J 1972; 133: 60-66.

26 Scott P J. Reflex Microscope-measurement in three dimensions. Proc Soc Photo Opt Instr Eng 1983; 368:124-128.

27 Lambrechts P, Vanherle G, Vuylsteke M, Davidson C L. Quantitative evaluation of the wear resistance of posterior dental restorations a new three dimensional measuring system. J Dent 1984; 12: 252-267.

28 Adams L P, Jooste C H, Thomas C J. An indirect in vivo method for quantification of wear of denture teeth. Dent Mat 1989; 5: 31-34.

29 Brickley M, Howell P G T. Measurement of changes in trabecular bone structure with age in an archaeological population. J Archaeo Science 1999; 26: 151-157.

30 Wassell R W, McCabe J F, Walls A W G. Wear characteristics in a two body wear test. Dent Mat 1994; 10: 269-274.

31 Shillingburgh H T, Grace C S. Thickness of enamel and dentine. J Southern California Dent Assoc 1973; 41: 33-52. 